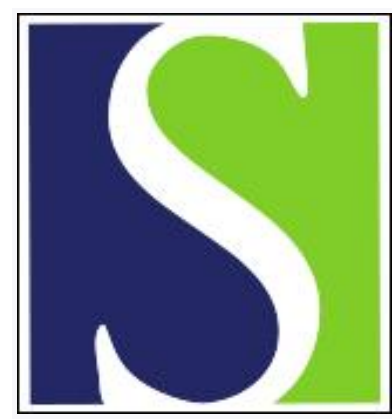

Scand J Work Environ Health 2010;36(6):445-448

https://doi.org/10.5271/sjweh.3075

Published online: 05 Aug 2010, Issue date: Nov 2010

Development of depressive symptoms and depression during organizational change - a two-year follow-up study of civil servants

by Netterstrøm B, Blønd M, Nielsen M, Rugulies R, Eskelinen L

Affiliation: Department of Occupational and Environmental Medicine, Bispebjerg University Hospital, 2400 Copenhagen NV, Denmark. bnet0002@bbh.regionh.dk

Refers to the following text of the Journal: 2006;32(6):443-462

The following article refers to this text: 2010;36(6):433-434

Key terms: civil servant; Denmark; depression; depressive symptom; follow-up study; longitudinal study; Major Depression Inventory; MDI; organizational change

This article in PubMed: www.ncbi.nlm.nih.gov/pubmed/20686739 


\title{
Development of depressive symptoms and depression during organizational change - a two-year follow-up study of civil servants
}

\author{
Bo Netterstrøm, MD, DrMed Sc, ${ }^{1}$ Morten Blønd, MD, ${ }^{2}$ Martin Nielsen, MD, ${ }^{1}$ Reiner Rugulies, PhD, ${ }^{3}$ Leena \\ Eskelinen, $P h D^{4}$
}

\begin{abstract}
Netterstrøm B, Blønd M, Nielsen M, Rugulies R, Eskelinen L. Development of depressive symptoms and depression during organizational change - a two-year follow-up study of civil servants. Scand J Work Environ Health. 2010;36(6):445-448.
\end{abstract}

Objective On 1 January 2007, Denmark went through a major reorganization, where most of its 275 municipalities and 14 counties merged into larger units. Our study aimed to examine the development of depressive symptoms and incident depression among employees affected by this organizational change.

Methods A total of 685 civil servants employed in the administration of 5 municipalities and 2 counties participated in the study. They answered a postal questionnaire, 8 months prior to and 16 months after the reorganization, regarding working conditions, psychosocial work environment factors, and depressive symptoms, based on the Major Depression Inventory (MDI). During the follow-up period of 2006-2008, 295 employees had experienced a merger with other workplaces (hereafter the merger group), 259 had got a new job (the new job group), and 131 who experienced no change in workplace served as the control group. The three groups were compared to each other for (i) mean score of MDI and (ii) incident cases of depression using general linear models and logistic regression analyses, separately by gender.

Results After adjustment of the MDI for age, occupation, supervisor function, and department at baseline in 2006, no significant differences in increase in MDI were found between the groups. The incidence of depression in the merger group was not significantly higher than the control group [women: odds ratio (OR) 1.5 ( $95 \%$ confidence interval [ $95 \% \mathrm{CI}]$ 0.6-3.9), men: OR 1.7 (95\% CI 0.2-18.7)], after adjustment for confounders.

Conclusion This study showed no significantly increased risk of depression or increase in depressive symptoms among employees exposed to organizational change as a part of a major local government reform.

Key terms Denmark; longitudinal study; Major Depression Inventory; MDI.

Depression is one of the most disabling disorders, ranking fifth on the list of disability-adjusted life years scores (1). The risk of absenteeism is approximately five times higher for patients with major depression compared to non-depressive persons (2). The one-year prevalence of major depression has been reported to be between $2-5 \%$ in several studies (3). Regarding lifetime prevalence, a recent review of 16 epidemiologic studies reported rates ranging from $3.0-24.4 \%$ with a mean lifetime prevalence of $11.7 \%$ (4). It is widely assumed that the aetiology of depression is multifactorial, involving genetics as well as biological and psychosocial factors $(5,6)$.
Studies of exposure to adverse psychosocial working conditions and its possible effect on the development of depression have been meta-analyzed by Stansfeld \& Candy (7). Based on 11 prospective studies, they concluded that adverse psychosocial working conditions are likely risk factors for the development of common mental disorders, including depression.

In a more recent review, Netterstrøm and colleagues (8) concluded that there was moderate evidence for a relationship between high psychological demands and low social support at work and the risk of developing depression. However, an indication of publication bias

1 Department of Occupational and Environmental Medicine, Bispebjerg University Hospital, Copenhagen, Denmark.

2 Clinic of Occupational Medicine, Nykøbing F Hospital, Nykøbing Falster, Denmark.

3 National Research Centre for the Working Environment, Copenhagen, Denmark.

4 Danish Institute of Governmental Research, Copenhagen, Denmark.

Correspondence to: Dr Bo Netterstrøm, Department of Occupational and Environmental Medicine, Bispebjerg University Hospital, 2400 Copenhagen NV, Denmark. [E-mail: bnet0002@bbh.regionh.dk]. 
weakens the evidence. In another review on the same topic, Bonde (9) cautioned against causal inference as working conditions were measured by self-report in the vast majority of studies examined. One possibility for assessing working conditions independent of self-report is to consider organizational changes as an exposure variable. Organizational changes might affect employees' health both by elevated job and status insecurity and through increased workload (10-18).

In Denmark, we had a chance to study the health effects of major organizational changes in a natural experiment. On 1 January 2007, 275 municipalities of the country were merged into 98 , and 14 counties were reduced to 5 regions. Typically, 2-4 units were merged, but 25 municipalities and 1 county were not merged. During the reform, a number of responsibilities were transferred between central and local government levels. All employees were given a job guarantee, but they had limited influence over their future place and content of work.

The objective of this study was to investigate whether these organizational changes were prospectively associated with an increase in depressive symptoms and the incidence of depression.

\section{Methods}

\section{Population}

The study population comprised white-collar employees in the municipal or county administration of five municipalities and two counties. The selection of these town halls was based on our knowledge about the future merger of four of the municipalities with others, and one of the counties with others, so that one municipality and one county remained unmerged with only minor changes in tasks. In November 2004, Statistics Denmark identified 2026 potential participants through a compilation of data regarding places of employment and salary codes. A questionnaire was sent to them in April 2006. After two reminders, 1190 employees completed the questionnaire. An unknown number of the 2026 in the population under study had left the labor market or got another job between November 2004 and April 2006. According to questionnaire answers, at least 187 had left their jobs before April 2006. In April 2008 , a similar questionnaire was sent to the baseline respondents. A total of 820 people responded ( $44 \%$ of the population under study), but due to a technical error in the reminders, it was only possible to analyze data for both years for 791 persons. During follow-up, 106 left the labor market, yielding a final study population of 685 people.

\section{Measures}

The independent variable (ie, membership of merger, new job, or control group) was defined by the organization where the participants worked in April 2008, according to the information given in the questionnaire. Of the 685 participants, 295 in 4 municipalities and 1 county were merged with other units by January 2007 . These individuals formed the merger group. The new job group consisted of the 259 participants who had taken up employment with another employer during follow-up. The control group comprised 131 people who worked at the same workplace during the whole period.

We included the following covariates (i) occupation (academic, clerk, social worker, technician, consultant, IT personnel and others), (ii) department (technical, school, social, health, administrative, other), (iii) supervisor function (having subordinates or not), (iv) gender, and (v) age (18-64 years), all self-reported in the baseline questionnaire.

The study endpoint was depressive symptoms and incident depression measured with the Major Depression Inventory (MDI) (19). The MDI consists of 12 questions about symptoms of depression within the last 2 weeks. The 6 response categories ranged from "at no time" $(0$ points) to "all of the time" (5 points). The MDI score was calculated as the sum of the score for each item. The highest obtainable score is 50 points as, in 4 of the questions, one has to choose the highest value of 2 questions. A score of $\geq 20$ is considered to reflect clinically relevant depression and was used here as the definition of depression (19). When analyzing this outcome, we excluded 82 participants with a MDI score of $>19$ at baseline, and thus we considered follow-up scores of $>19$ as incident cases of depression.

\section{Statistical methods}

All analyses were performed in Statistical Package in the Social Sciences (SPSS), version 11 (SPSS Inc, Chicago, IL, USA), using general linear models in the analyses of changes in MDI scores and logistic regression in the analyses of incident depression.

\section{Results}

In the merger group, women were significantly older compared to the other groups. The new job group consisted of significantly more academics and employees in technical departments. Civil status or percentage of supervisors did not differ significantly between the exposure groups. 
Table 1. Distribution of mean score of Major Depression Inventory (MDI) in 2006 and change in scores during follow up among female and male participants. [95\% $\mathrm{Cl}=95 \%$ confidence interval.]

\begin{tabular}{|c|c|c|c|c|c|c|c|c|c|c|c|c|}
\hline \multirow[t]{3}{*}{ Year } & \multicolumn{6}{|c|}{ Women } & \multicolumn{6}{|c|}{ Men } \\
\hline & \multicolumn{2}{|c|}{ Merged $(\mathrm{N}=236)$} & \multicolumn{2}{|c|}{ New job $(N=166)$} & \multicolumn{2}{|c|}{ Control $(\mathrm{N}=100)$} & \multicolumn{2}{|c|}{ Merged $(N=59)$} & \multicolumn{2}{|c|}{ New job $(\mathrm{N}=93)$} & \multicolumn{2}{|c|}{ Control $(\mathrm{N}=31)$} \\
\hline & Mean & $95 \% \mathrm{Cl}$ & Mean & $95 \% \mathrm{Cl}$ & Mean & $95 \% \mathrm{Cl}$ & Mean & $95 \% \mathrm{Cl}$ & Mean & $95 \% \mathrm{Cl}$ & Mean & $95 \% \mathrm{Cl}$ \\
\hline MDI 2006 & 10.0 & $8.8-11.1$ & 9.3 & $7.9-10.6$ & 9.3 & $7.5-10.9$ & 7.5 & $5.2-9.6$ & 8.7 & $7.2-10.1$ & 5.4 & $2.3-8.4$ \\
\hline $\begin{array}{l}\text { MDI 2008- } \\
2006\end{array}$ & 0.32 & $-0.9-1.6$ & -0.57 & $-2.7-0.9$ & 0.08 & $-1.9-1.8$ & -0.12 & $-1.8-1.6$ & -0.84 & $-2.2-0.5$ & 0.97 & $-1.4-3.3$ \\
\hline $\begin{array}{l}\text { MDI 2008- } \\
2006^{\text {a }}\end{array}$ & 0.46 & $-0.6-1.5$ & -0.81 & $-2.1-0.5$ & -0.15 & $-1.7-1.5$ & -0.44 & $-1.9-1.1$ & -0.33 & $-1.6-0.9$ & 0.17 & $-2.1-2.4$ \\
\hline
\end{tabular}

a MDI in 2006 adjusted for age, supervisor function, department, occupation.

Table 2. Incidence of depression and odds ratio (OR) for depression according to exposure group among 431 female and 172 male participants with Major Depression Inventory (MDI) score $<20$ in 2006. [95\% Cl = 95\% confidence interval.]

\begin{tabular}{|c|c|c|c|c|c|c|c|c|c|c|c|c|}
\hline \multirow[t]{2}{*}{ Group } & \multicolumn{6}{|c|}{ Women } & \multicolumn{6}{|c|}{ Men } \\
\hline & $\mathrm{N}$ & $\begin{array}{c}\text { 2-year } \\
\text { incidence } \\
(\%)\end{array}$ & $\mathrm{OR}^{\mathrm{a}}$ & $95 \% \mathrm{Cl}$ & $O R^{b}$ & $95 \% \mathrm{Cl}$ & $N$ & $\begin{array}{c}\text { 2-year } \\
\text { incidence } \\
(\%)\end{array}$ & $\mathrm{OR}^{\mathrm{a}}$ & $95 \% \mathrm{Cl}$ & $\mathrm{OR}^{\mathrm{b}}$ & $95 \% \mathrm{Cl}$ \\
\hline Merged & 201 & 10.4 & 1.5 & $0.6-3.8$ & 1.5 & $0.6-3.9$ & 53 & 5.7 & 1.5 & $0.1-15.2$ & 1.7 & $0.2-18.7$ \\
\hline New job & 141 & 12.1 & 1.9 & $0.7-5.1$ & 2.0 & $0.8-5.6$ & 89 & 2.4 & 0.7 & $0.1-8.0$ & 1.1 & $0.1-15.6$ \\
\hline Control & 89 & 6.7 & 1.0 & & 1.0 & & 30 & 3.3 & 1.0 & & 1.0 & \\
\hline
\end{tabular}

adjusted for age.

${ }^{\mathrm{b}}$ Adjusted for age, leadership, department, and occupation.

Table 1 gives the MDI scores in 2006 and changes during follow-up in the three groups. No significant differences were detected, regardless of whether analyses were adjusted for confounders or not.

During follow-up, there were 50 incident cases of depression, 43 among women and 7 among men. Among women, the odds ratio (OR) for incident depression was 1.5 [ $95 \%$ confidence interval $(95 \% \mathrm{CI}) 0.6-3.9]$ in the merger group and $2.0(95 \% \mathrm{CI} 0.8-5.6)$ in the new job group after adjustment for occupation, department, supervisor position, and age compared to the control group (table 2). Among men, the OR was 1.7 (95\% CI 0.2-18.7) for the merger group. The prevalence of depression at baseline and in 2008 within the full sample was almost the same (10.2\% and $9.8 \%$ respectively).

\section{Discussion}

The main strength of this study is its use of an objective classification of the exposure to organizational changes as the independent variable.

A limitation is selection bias, as only half of the original study population completed both questionnaires. The non-respondents were, however, approximately evenly distributed among the municipalities; the group that responded to the baseline questionnaire only did not differ with regard to the MDI score (9.11 among followup participants and 9.13 among dropouts), gender, and age from the group that participated in the follow-up.

Depression is measured by the use of questionnaires, which might lead to some information bias, although MDI is well validated (19).

The main weakness of this study, and a possible cause of the limited increase in depressive symptoms from baseline to follow-up, could be considerable negative expectations and stressful preparations regarding the organizational reform. This could mean that at baseline in April 2006 - only eight months before the implementation of the reform - the level of depressive symptoms was already elevated. In 2000 , the prevalence of depression (MDI $>19$ ) was $8 \%$ in Denmark (20), which is somewhat lower than the $10 \%$ measured in this study. The mean MDI score was 8.8 compared to 9.1 in this study. The higher level of depressive symptoms in our study is particularly remarkable, considering that we included only working people, whereas the study from 2000 also included people on long-term sickness absence, unemployment, and disability pension.

It must be considered that the study might have lacked power. Among women, the OR for incident 
depression were 1.5 and 2.0 in the merged and the new job groups, respectively, compared with the control group. These OR might have been significant in a larger sample.

Two previous studies have reported that job insecurity due to organizational change was associated with depression $(14,16)$. In a Danish study, there was a prospective association between job insecurity and depressive symptoms among men, but not among women (21). In principle, job insecurity should be less of a problem in our study, as there was a formal job guarantee. However, interviews indicated that some employees did not perceive the promises as valid, or had a fear of being left in a job they would not consider acceptable.

In conclusion, this study showed no significantly increased risk of depression or increase in depressive symptoms among employees exposed to organizational change during a major structural reform.

\section{Acknowledgements}

This study was sponsored by the Danish Working Environment Research Fund. The authors declare no conflicts of interests.

\section{References}

1. Murray CJ, Lopez AD. Global mortality, disability, and the contribution of risk factors: Global Burden of Disease Study. Lancet. 1997;349(9063):1436-42.

2. Broadhead WE, Blazer DG, George LK, Tse CK. Depression, disability days, and days lost from work in a prospective epidemiologic survey. JAMA. 1990;264(19):2524-8.

3. Horwath E, Cohen R, Weissman M. Epidemiology of depressive and anxiety disorders. In: Tsuang M, Tohen M, editors. Textbook in psychiatric epidemiology. New York (NY): Wiley-Liss; 2002. p 389-426.

4. Goodwin R, Jacobi F, Bittner A, Wittchen H-V. Epidemiology of mood disorders. In: Stein D, Kupfer D, Schtzberg A, editors. Textbook of mood disorders. Washington (DC): American Psychiatric Publishing; 2006. p 33-54.

5. Harris T. Recent developments in understanding the psychosocial aspects of depression. Br Med Bull. 2007;57:17-32.

6. Lorant V, Deliege D, Eaton W, Robert A, Philippot P, Ansseau $\mathrm{M}$. Socioeconomic inequalities in depression: a meta-analysis. Am J Epidemiol. 2003;157(2):98-112.

7. Stansfeld S, Candy B. Psychosocial work environment and mental health - a meta-analytic review. Scand J Work Environ Health. 2006;32(6):443-62.
8. Netterstrøm B, Conrad N, Bech P, Fink P, Olsen O, Rugulies R, Stansfeld $\mathrm{S}$. The relation between work-related psychosocial factors and the development of depression. Epidemiol Rev. 2008;30:118-32.

9. Bonde JPE. Psychosocial factors at work and the risk of depression: a systematic review of the epidemiological evidence. Occup Environ Med. 2008;65:438-45.

10. Kivimäki M, Vahtera J, Pentti J, Ferrie JE. Factors underlying the effect of organisational downsizing on health of employees: a lingitudinal cohort study. BMJ. 2000;320(7240):971-5.

11. Vahtera J, Kivimäki M, Pentti J, Linna A, Virtanen M, Virtanen $\mathrm{P}$, et al. Organisational downsizing, sickness absence and mortality: 10-town prospective cohort study. BMJ. 2004;328:555-9.

12. Westerlund H, Ferrie JE, Hagberg J, Jeding K, Oxenstierna G, Theorell T. Work place expansion, long term sickness absence, and hospital admission. Lancet. 2004;363:1193-7.

13. Hertting A, Theorell T. Physiological changes associated with downsizing of personnel and reorganisation in the health care center. Psychother Psychosom. 2002;71:117-22.

14. Ferrie JE, Shipley MJ, Stansfeld SA, Marmot MG. Effects of chronic job insecurity and change in job security on self reported health, minor psychiatric morbidity, physiological measures, and health related behaviours in British civil servants: the Whitehall II study. J Epidemiol Community Health. 2002;56(6):450-4.

15. Kivimäki M, Vahtera J, Elovainio M, Pentti J, Virtanen M. Human costs of organizational downsizing: comparing health trends between leavers and stayers. Am J Com Psychol. 2003;32:57-67.

16. Kivimäki M, Honkonen T, Wahlbeck K, Elovainio M, Pentti J, Klaukka, T, et al. Organizational downsizing and increased use of psychotropic drugs among employees who remain in employment. J Epidemiol Community Health. 2007;61(2):154-8.

17. Swaen GMH, Bultmann U, Kant I, Van Amelsvoort LGPM. Effects of job insecurity from a workplace closure threat on fatigue and psychological distress. J Occup Environ Med. 2004;46(5):443-9.

18. Westerlund H. Health changes in a changing labor market [dissertation]. Stockholm: Karolinska Institutet; 2005.

19. Olsen LR, Jensen DV, Noerholm V, Martiny K, Bech P. The internal and external validity of the Major Depression Inventory in measuring severity of depression. Psychol Med. 2003;33:351-6.

20. Olsen LR, Mortensen EL, Bech P. Prevalence of major depression and stress indicators in the Danish general population. Acta Psychiatr Scand. 2004;109(2):96-103.

21. Rugulies R, Bultmann U, Aust B, Burr H. Psychosocial work environment and incidence of severe depressive symptoms: prospective findings from a 5-year follow-up of the Danish work environment cohort study. Am J Epidemiol 2006;163(10):877-87.

Received for publication: 16 December 2009 